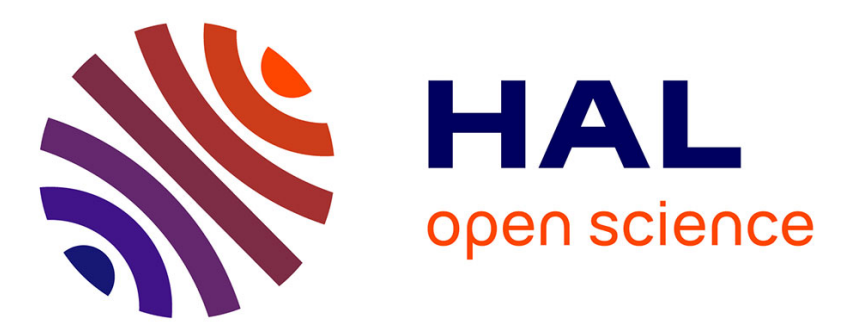

\title{
Dissociations between perception and awareness in hemianopia
}

Sylvie Chokron, Lucas Dubourg, Clémentine Garric, Fiora Martinelli, Céline Perez

\section{- To cite this version:}

Sylvie Chokron, Lucas Dubourg, Clémentine Garric, Fiora Martinelli, Céline Perez. Dissociations between perception and awareness in hemianopia. Restorative Neurology and Neuroscience, 2020, 38 (3), pp.189-201. 10.3233/RNN-190951 . hal-03031522

\section{HAL Id: hal-03031522 \\ https://hal.science/hal-03031522}

Submitted on 30 Nov 2020

HAL is a multi-disciplinary open access archive for the deposit and dissemination of scientific research documents, whether they are published or not. The documents may come from teaching and research institutions in France or abroad, or from public or private research centers.
L'archive ouverte pluridisciplinaire HAL, est destinée au dépôt et à la diffusion de documents scientifiques de niveau recherche, publiés ou non, émanant des établissements d'enseignement et de recherche français ou étrangers, des laboratoires publics ou privés. 


\section{Dissociations between perception and awareness in hemianopia}

Sylvie CHOKRON ${ }^{2}$, Lucas DUBOURG ${ }^{1.2}$, Clémentine GARRIC ${ }^{3}$, Fiora MARTINELLI ${ }^{2}$ and Céline PEREZ ${ }^{1,2}$

${ }^{1}$ Institut de Neuropsychologie, Neurovision, NeuroCognition, Fondation Ophtalmologique Adolphe de Rothschild, Paris, France

${ }^{2}$ Integrative Neuroscience and Cognition Center, CNRS, UMR 8242 et Université ParisDescartes, Paris, France

${ }^{3}$ Laboratoire de Sciences Cognitives et Affectives, SCALab, CNRS UMR 9193, Faculté de Médecine, Pôle recherche et Université de Lille, Lille, France

Corresponding Author: Sylvie Chokron, Institut de Neuropsychologie, Neurovision, Neurocognition, Fondation Ophtalmologique Rothschild, 3 rue André Dubois, 75019 Paris, France. Tel : 33-1-48036672 Fax: 33-1-48036551 sylvie.chokron@gmail.com

Running Title: Perception and awareness in hemianopia

\section{Abstract}

After a lesion of the retrochiasmal pathways, the most common visual defect is homonymous hemianopia where, for each eye, patients are blind for the contralesional visual field (VF). Hemianopia has been studied both regarding its deleterious consequences on perceptual, cognitive and motor tasks as well as because it represents an interesting model of vision loss after a unilateral lesion of the occipital lobe. From a behavioural point of view, in addition to exhibiting a severe deficit in their contralesional visual field, hemianopic patients may present also several dissociations between perception and awareness. First of all, hemianopic patients may be unaware of their visual field defect, suffering from anosognosia. Second, they may also present unconscious visual abilities in the blind hemifield now usually referred to as blindsight. In addition, it was recently demonstrated that hemianopic patients may also suffer from a subtle deficit in their ipsilesional visual field they are not aware of, called sightblindness (the reverse case of 'blindsight'). Finally, hemianopic patients may also present visual hallucinations in their blind field although not systematically aware of the fact these are unreal perceptions. . In the present paper we describe the four above-mentioned patterns of dissociation between perception and awareness in hemianopic patients after a left or right unilateral occipital lesion and discuss the implications of these phenomena for models of visual processing and rehabilitation of visual field defects in hemianopic patients.

Key words : Homonymous Hemianopia, blindsight, anosognosia, hallucinations, awareness, occipital 


\section{Homonymous hemianopia: definition, etiology and lesion location}

Clinically, the most common visual field defect to follow a retrochiasmatic lesion is homonymous hemianopia (HH) (Zihl, 2011). In most cases, the hemianopic defect is congruent: the losses to the contralesional field of each eye are symmetric to the point that they can be superimposed (Zihl, 2011) (see Figure 1). 70\% of strokes that involve the posterior cerebral arteries lead to HH (Pambakian \& Kennard, 1997). On the other hand, HH occurs in $30 \%$ of patients that have suffered a stroke (Zhang, Kedar, Lynn, Newman, \& Biousse, 2006). Regarding lesion side, our group recently demonstrated that the defects in hemianopic patients, as well as the cortical reorganization that follow a V1 lesion, can depend on the hemisphere in which the lesion occurs (Cavezian et al., 2010; Perez et al., 2013). These results suggest the existence of hemispheric specialization at the occipital level, which could influence the adaptive and reorganizational phenomena that follow visual-cortex lesions and visual field defects (for a discussion, see Perez et al., 2013 and Cavezian et al., 2015).

Although homonymous hemianopia is generally considered only as a visual field defect, below we present and discuss why this deficit is an interesting model to study the dissociation between perception and awareness. 


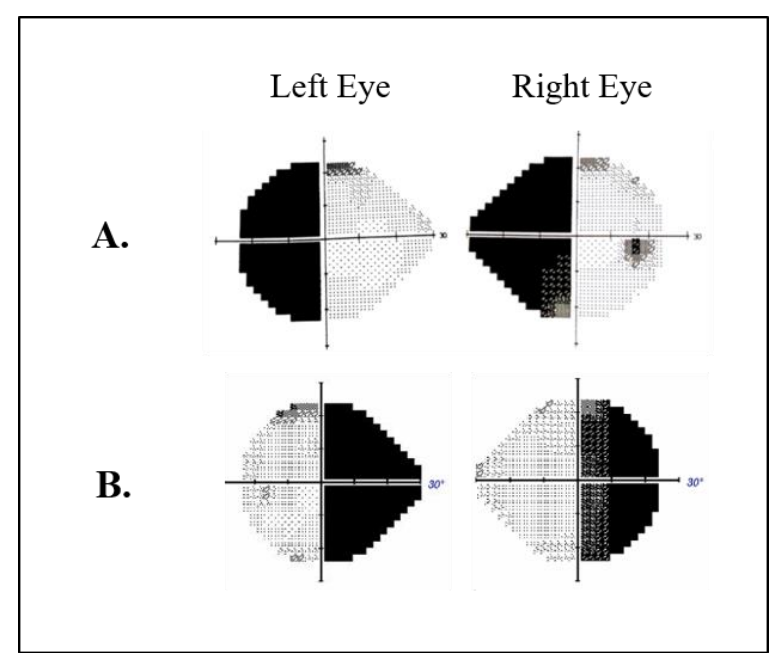

Figure 1. Illustration of the visual field deficit in left $H H(A)$ and right $H H(B):$ Humphrey Automated visual perimetry from two hemianopic patients, in both eyes.

\section{Anosognosia}

Lesions in the primary visual cortex (V1) cause a loss of conscious access to most visual information in the contralesional visual field (Holmes, 1918; Weiskrantz, Warrington, Sanders, \& Marshall, 1974). However, hemianopic patients might be unaware of their visual field defect and may suffer from anosognosia. In 1885, Von Monakow published the first description of unawareness of disorders due to brain lesions. Subsequently, Babinski (1918) coined the term anosognosia to describe this phenomenon ranging from uncritical underestimation to explicit, intractable denial of the clinical signs including cortical blindness, spatial neglect, cortical deafness, hemiplegia, word deafness, dyslexia, dysphasia (see for review and discussion, Gainotti, 2019). In a seminal paper on this topic, Bisiach et al (1986) investigated awareness of motor and visual-field defects in 97 right brain-damaged subjects. Both kinds of anosognosia were found to be double-dissociated and anosognosia for hemianopia fails to show any association to unilateral neglect. In addition, four of the 10 patients with severe anosognosia for hemianopia had minimal (if at all) anosognosia for hemiplegia. These findings confirm the previous crucial observation of Anton (1899) that his patient Mercz., although quite unaware of her blindness, was painfully conscious of her mild verbal disorders. In addition, in Bisiach 
et al' study (1986), important unawareness of hemianopia was found to be much more frequent than unawareness of motor impairment. These authors proposed that the lesions involving the visual pathways could be very closed to the brain area damage responsible for disordered monitoring of the resulting dysfunction. Indeed, as Breitmeyer (2014) stated, patients will visual field defects, may thus fail to acknowledge their visual deficits and appear as being cognitively blind to their neurological blindness. Critchley (1949) identified various degrees of awareness of the visual field defect: (1) total lack of awareness of the deficit, (2) unawareness of the defect itself, but a recognition of the consequences of the defect (e.g. frequent bumping into objects or persons), (3) Attribution of the deficit to external causes (e;g; lack of illumination), (4) Aware that 'there is something wrong' with vision, although the deficit itself cannot be defined or described, (5) Awareness of a lateralized visual defect, although the patient think that it is an eye problem instead of a visual field defect, (6) full awareness of the hemianopia defect. As a matter of fact, in most of the cases, the patient does not experience a 'black spot' in place of his/her blind visual field. Indeed, the hemianopia can be considered as a reduction of the visual field, with new peripheral borders, leading to conscious perception in only half of the previous visual field. Along those lines, being conscious of the absence of visual stimulation in the contralesional visual field might be particularly difficult thus leading to anosognosia of the visual field loss. In this way, Levine (1990) proposed that a post-chiasmatic lesion does not necessarily provide any specific information about the direct experience that uniquely specifies the defect. For this reason, according to Zihl (2000), unawareness of the visual field defect can be commonly found in patients with normal intellectual functions. Indeed, this author insists on the fact that due to the absence of an immediate sensation, hemianopic patients need to infer the presence of the visual field defect from failures resulting from it (e.g. car accidents, falls, difficulties in reading etc...). In addition, according to Levine (1990) discovery of visual loss requires 'the ability to change the mental set or outlook based 
on evidence from the external world' and is mainly dependent upon mental flexibility (Zihl, 2000). Regarding the neuro-anatomical correlates of anosognosia for hemianopia, clinical and experimental reports (see for example Bisiach et al, 1986) demonstrate that various types of lesions involving different anatomic regions can lead to anosognosia in hemianopia and that conversely, similar lesions are not always associated with anosognosia. In 1997, Celesia, Brigell and Vaphiades showed that twenty of 32 patients with hemianopia $(62 \%)$ had anosognosia of their visual deficit. Anosognosia for hemianopia was observed in 16 of 26 right-brain damaged patients $(62 \%)$, and was also observed in four of six left-brain damaged patients (67\%). As previously found in Bisiach and colleagues study (1986), anosognosia for hemianopia was clearly dissociated from anosognosia for neglect and, for 14 patients did appear in the absence of cognitive impairment. Interestingly and as we will further discuss, patients with positive spontaneous visual phenomena (PSVP), either phosphenes, photopsia, visual hallucinations, or palinopsia, were usually aware of their deficit. Indeed, only three of 12 patients with PSVP had visual anosognosia. Regarding the neuroanatomical correlates of anosognosia for hemianopia, Celesia, et al. (1997) could not identify any cortical areas specific for awareness of the visual deficit. Lesions limited to V1, V2, and portions of V3 or their connections from the lateral geniculate nucleus were sufficient to produce anosognosia for the visual field defect. These findings infirm the previous study of Koehler, Endtz, Velde, and Hekster (1986) who proposed (on the basis of CT correlations) that patients aware of their hemianopia had purely occipital lesions, whereas patients unaware of their hemianopia had more anterior lesions such as parietal lesions or lesions interrupting the associative pathways from the primary visual cortex. Interestingly, in search for a hemispheric specialization for unawareness of the visual deficit, Celesia et al. (1997) found that sixteen of 20 patients with anosognosia for hemianopia had lesions of the right hemisphere, as did four of seven patients with left brain-damage. According to these findings, anosognosia for hemianopia could be 
preferentially linked to right hemisphere lesions such as what has been proposed for left unilateral spatial neglect (Heilman and Abell, 1980). As emphasized by Celesia et al. (1997) and has we will discuss at the end of the paper, anosognosia for hemianopia could be linked to the other behavioral phenomena we present below. Indeed, in addition to this dissociation between the presence of a perceptual deficit and its awareness, blindsight, that is the ability to process stimuli in the blind visual field in the absence of conscious detection, depicts another dissociation between perception and awareness.

\section{/Insert Table 1/}

\section{Blindsight}

\subsection{Definition}

Since pioneer work of Weizkrantz et al. (1974), we know that from a behavioral perspective, hemianopic patients can exhibit implicit residual capacities in the contralesional, so-called "blind" visual field, despite exhibiting a severe visual-field defect. Such capacities are usually referred to as blindsight, a term proposed by Weiskrantz et al. (1974). In a seminal study, Pöppel, Held and Frost (1973) found that four patients could accurately steer their gaze toward a flashing light presented in their blind field yet did not report having perceived the stimulation. Subsequently, several visual residual functions were tested in the patient D.B. through forcedchoice methods (Sanders, Warrington, Marshall, \& Wieskrantz, 1974). D.B. was asked to distinguish the orientation of stripes (horizontal $v s$. vertical), to identify letters (X $v s$. $\mathrm{O})$, to reach, grasp, or sch his gaze towards a stimulus in his contralesional visual field (Sanders et al., 1974). Interestingly, in addition to performing significantly above chance in all the tasks, the patient never reported any conscious perception of the stimuli in his blind field. These results led to the first apparition of the term blindsight. Later, another blindsight patient named G.Y. reported awareness of certain stimuli despite not attesting to any concrete visual perception of 
them (Weiskrantz, Barbur \& Sahraie, 1995). Consequently, blindsight was classified into two types: type $I$, the ability to discriminate specific attributes of a stimulus in the contralesional visual field without any awareness of it; and type II, exhibiting objective performance and subjective performance in the blind visual field above chance level, without any conscious detection of the stimuli (Brogaard, 2015; Weiskrantz, 1998).

Typically, type II blindsight corresponds to patients that exhibit significant objective performance scores in their blind visual field and report having felt something in the absence of conscious perception (for a review, see Brogaard, 2015). As discussed below, experimental design is crucial for enabling researchers to ascertain and classify blindsight among patients. Diagnosing blindsight implies not only an accurate measure of objective performance, but also a well-controlled and interpretable measure of subjective experience. On one hand, the stimulipresentation parameters (e.g. duration, contrast, size or location) and the response mode (e.g. verbal or motor; for a review, see Fayel et al., 2014) of a given experiment activate dissimilar objective abilities that may differ among subjects. On the other hand, although blindsight is defined by an absence of subjective experience, the literature reflects debates on the methodology used to assess patients' awareness (Overgaard, Fehl, Mouridsen, Bergholt, \& Cleeremans, 2008). For example, use of a binary scale (i.e. Aware vs. Unaware) may compel a subject to report being "unaware" of a stimulus despite having experienced a minor degree of awareness (Overgaard et al., 2008; Overgaard, 2011). Distinct responses on G.R.'s level of awareness in the blind visual field were found according to whether the patient was tested using a binary scale (Seen vs. Not Seen) or the Perceptual Awareness Scale (PAS) (Ramsøy \& Overgaard, 2004), which comprises four levels: Clear Experience, Almost Clear Experience, Weak Glimpse and Not Seen. Indeed, when asked to process a stimulus in his contralesional visual field and subsequently report a dichotomous answer (Seen vs. Not Seen), G.R. exhibited a typical type-I-blindsight profile (i.e. implicit processing without awareness of the stimuli). 
However, when assessed by the PAS, he significantly reported some degree of awareness in the presence of stimuli in his contralesional visual field, thus exhibiting a type-II profile. Despite this proven drawback, binary questionnaires are still widely used to study blindsight; indeed, very few researchers use graduated measurements of perception (Overgaard et al., 2008; Mazzi, Bagattini, \& Savazzi, 2016). However, understanding the nature of the patients' perceptual experience in their blind field remains an important issue as discussed below.

\section{Perceptual experience in the blind visual field}

Three distinct hypotheses have been proposed in order to account for blindsight. On one hand, some studies have emphasized that blindsight is based on unconscious perceptual abilities (Sanders et al., 1974; Leh, 2006). On the other hand, some authors have proposed that blindsight relies on residual remaining 'normal' vision (Cowey, 2009; Hadid \& Lepore, 2017). Along those lines, blindsight is seen as reduced but normal residual vision. Finally, blindsight has also been interpreted as degraded, abnormal vision, that is a different form of vision than 'normal' visual perception as if looking in deforming glasses. This latter hypothesis arose from studies on type II blindsight and has been described as a "conscious experience, though of a very different nature to that of normal vision" (Mazzi et al., 2016; Weiskrantz, 2009; Kentridge, 2015).

These three hypotheses are still in debate and it is difficult to disentangle them since most of the research in this area are case studies showing one or the other type of blindsight. Indeed, group studies using both objective visual detection and discrimination tasks and subjective perceptual scales could permit to evaluate what type of perceptual experience is the most frequent in hemianopic patients. In addition, group studies are also needed to study the occurrence of blindsight. Given the fact that blindsight stimulation has been proved to induce visual restoration (see Chokron et al., 2008 and Perez and Chokron, 2014 for review), it would be important for clinicians to know what kind of perceptual experience is the most observed in 
hemianopic patients in order to design the more appropriate therapy. However, only a few studies have been conducted on groups of patients, and most of them have provided only indirect information on the occurrence of blindsight. In a group of 8 patients, Perenin and Jeannerod (1975) found blindsight in six out of eight patients but they did not use any perceptual subjective scale. Studying the anatomical bases of blindsight in seventeen hemianopic patients, Ajina, Pestilli, Rokem, Kennard and Bridge (2015) distinguished between twelve of whom they classified as "blindsight positive" and five as "blindsight negative", based on two alternative forced-choice detection tasks related to the contralesional visual field. Using the Redundant Signal Effect (RSE) task involving indirect flash presentation to assess visual information processing in the blind and in the healthy visual field, only one out of 20 patients (5\%) exhibited faster responses after simultaneous presentation of visual stimuli in the two visual fields, compared to single visual stimulation in the preserved field, expected for blindsight (Marzi, Tassinari, Aglioti, \& Lutzemberger, 1986). Thus, in this study, the incidence of blindsight was only 5\%. In another study, (Sahraie, Trevethan, MacLeod, Urquhart, \& Weiskrantz, 2013), blindsight incidence was evaluated among nineteen patients by measuring their pupil responses to visual stimuli presented in the hemianopic visual field, which reflects residual visual reflexes. These authors found a blindsight incidence of 70\% (Sahraie et al., 2013), however, in this study it was an indirect measure of blindsight and not a direct measure of unconscious visual capacities in the blind visual field.

Recently we sought to investigate objective and subjective perceptual experience in a group of 8 complete post-stroke hemianopic patients (Garric et al., 2019). To do so, patients firstly performed a letter detection and identification tasks (is it a $\mathrm{X}$ or a $\mathrm{O}$ ?) to evaluate objective perceptual abilities in the two visual fields. Here, the objective detection task was performed on a classical binary scale: "Something was presented" vs. "Nothing was presented". Secondly patients were submitted to the Sensation Awareness Scale (SAS) in order to 
investigate the nature of the perceptual experience in their blind visual field, which has only been examined in single-case studies so far. In this way, during the detection and identification tasks, after each trial, the patient was asked to choose the most appropriate assertion: [1] I did not see anything; [2] I don't think that I saw anything, but I am not sure; [3] I felt something; [4] I saw something; and [5] I clearly saw something and can identify it. The assertion 'I felt something' was added in order to let a chance to the patient to express that he had a sensation that could be different from a visual sensation. As a matter of fact, in clinical practice, patients often 'feel' the presence of something although being unable to report a visual sensation per se. Subjective performance was calculated based on the SAS and compared to the objective performance, which was evaluated through the forced-choice detection and identification tasks. In this way, we were able to reclassify our homonymous hemianopic patients according to the dissociation between objective and subjective performance and by different concepts of blindsight described in the literature. As a matter of fact, using both experimental tasks investigating detection and categorization tasks in the blind visual field as well as the SAS questioning the nature of the perceptual experience lead to four distinct profiles that could theoretically be found in hemianopic (and perhaps other) patients:

1. Absence of blindsight: objective performance and subjective performance both being at chance level.

2. Type I blindsight: objective performance above chance level, combined with a lack of statistically significant subjective sensitivity.

3. Type II blindsight: objective performance and subjective performance both being above chance level.

4. Blindsense: objective performance at chance level combined with a statistically significant subjective performance (previously unreported phenomenon). 
Interestingly, our findings showed that only one of the eight complete-HH patients met the criteria for blindsight. More importantly, our SAS enabled us to identify a previously unreported dissociation, which we characterized as blindsense, in four of the eight complete$\mathrm{HH}$ patients. Specifically, these four patients exhibited better-than-chance sensitivity to the presence of a stimulus on the subjective scale, despite being unable to identify the stimulus during the forced-choice task. Moreover, three out of the four blindsense patients presented a significant subjective sensitivity using the gradual SAS scale while being at chance level on the binary detection task. These findings underline the need to investigate not only objective perceptual abilities in the blind visual field of hemianopic patients but also their degree of awareness and suggest that blindsight is not as frequent as previously thought in complete poststroke hemianopic patients and in any case is far from being the most common dissociation between perception and awareness.

According to several studies, blindsight could depend on sparse surviving islands in the primary cortex (V1) (Campion, Latto, \& Smith, 1983; Fendrich, Wessinger, \& Gazzaniga, 2001). However, blindsight was also observed in patients lacking a functional primary visual cortex (Ajina, Pestilli, Rokem, Kennard, \& Bridge, 2015; Mazzi et al., 2016) as well as in monkeys with complete ablation of V1 (Stoerig \& Cowey, 1997). Indeed, Stoerig, (2006) has concluded that blindsight can occur without any functional portion of the primary visual cortex. Confirming this hypothesis, researchers have shown that blindsight could be mediated by subcortical pathways that bypass V1, such as the superior colliculus pathway and the dorsal lateral geniculate nucleus (dLGN) pathways. Moreover, several recent studies have underscored the roles of the ipsilateral hemisphere and the corpus callosum in processing of stimuli in the contralesional visual field of $\mathrm{HH}$ patients (Bridge, Thomas, Jbabdi, \& Cowey, 2008; Celeghin et al., 2017; Leh, 2006). 
Contrary to the case of blindsight, which has been extensively studied in hemianopic patients, vision quality in the central visual field and in the ipsilesional visual field of these patients has scarcely been assessed, and moreover, has traditionally been assumed to be fully preserved. However, as we discuss below, hemianopic patients may present a subtle deficit in their ipsilesional (thought to be healthy) visual field they are not aware of.

\section{Sightblindness}

Hess and Pointer (1989) were among the first authors to demonstrate that spatial and temporal sensitivities were lower in the ipsilesional visual field of hemianopic patients than in control subjects. In the same vein, Rizzo and Robin (1996), followed by Poggel, Treutwein and Strasburger (2011), confirmed that hemianopic patients can exhibit lower sensitivity to signals, compromised processing of temporal information and longer reaction times in both contralesional and ipsilesional visual fields, as compared to control participants. By studying a patient one week before and six months after a surgical intervention (embolization of an arteriovenous malformation in the right occipital lobe) we investigated a few years ago the performance in her right ipsilesional visual field (Peyrin et al., 2006). We addressed the role of the right visual cortex on local analysis (based on the high spatial frequency content of scene stimuli) and global analysis (based on the low spatial frequency content) of visual information in scenes. Results clearly confirmed that damage to the right primary visual cortex (V1) induces a decrease in performance in the right ipsilesional visual field. By the way, the patient was found even before surgery to perform with lesser accuracy and higher reaction times in the right ipsilesional visual field for all types of scenes compared to performance in healthy controls and presented an additional deficit for global analysis (based on low spatial frequencies) in her right ipsilesional visual field after surgery. This study led us to hypothesize that the right occipital lobe could be involved in the processing of the global aspects of a visual scene (low spatial 
frequencies) in both visual fields leading thus to a massive visual field defect in the contralesional visual field and to a weaker visual deficit in the ipsilesional visual field.

Whereas Schadow et al. (2009) found deficits in the early and late visual processing of Gestalt patterns in the ipsilesional visual field, Paramei and Sabel (2008) reported that hemianopic patients exhibited diminished ability to detect fragmented targets among a noisy background in the ipsilesional visual field. In addition, Bola, Gall and Sabel (2013a) confirmed these findings and reported processing-speed deficits in a simple detection task in the ipsilesional visual field. The authors termed this phenomenon sightblindness, as the reverse situation of blindsight (Bola, Gall, \& Sabel, 2013b): the former referring to visuo-attentional deficits in the ipsilesional visual field, whereas the latter refers to residual (although implicit as discussed above) visual abilities in the controlateral visual field (CVF) that are highlighted in forced-choice tasks (e.g., Weiskrantz et al., 1974; Leopold, 2012). Interestingly, hemianopic patients are not supposed to be aware neither of residual capacities in their contralesional visual field in the case of blindsight nor of their subtle visual deficit in the ipsilesional visual field in the case of sightblindness.

Along those lines, and as recently suggested, neither the central visual field (Cavézian et al., 2010; 2015; Perez et al., 2013) nor the IVF of hemianopic patients (Bola et al., 2013a; 2013b; Sanchez-Lopez et al., 2019) appear to be fully intact or functional. In line of these findings, it was also demonstrated that cortical reorganization may be observed not only in the lesioned but also in the healthy hemisphere after a unilateral occipital damage acquired in childhood (Mikellidou et al., 2019). Moreover, as we proposed, the nature of the task and the type of stimulus may determine the central and ipsilesional visual deficit and the pattern of cortical activation of hemianopic patients (Cavézian et al., 2010, 2015; Perez et al., 2013, Chokron, Perez, \& Peyrin, 2016). As a matter of fact, recently, we specifically investigated the effect of lesion side on the nature and severity of the ipsilesional deficit (Cavézian et al., 2015). 
In this study, five left and five right hemianopic patients were presented filtered (high or low spatial frequencies) as well as non-filtered scenes in their IVF during a detection and a categorization task. Right brain-damaged patients with left hemianopia made more errors for categorizing scenes in their IVF than did their matched controls, regardless of the spatial frequency content of scene. In contrast, left brain-damaged patients with right hemianopia made more errors than did the controls only when categorizing high spatial frequency scenes. Interestingly, in both tasks (detection and categorization), the right brain-damaged patients performed worse in their IVF than did the left brain-damaged patients. Together, these studies among right brain-damaged patients suffering from left homonymous hemianopia raise the question of the integrity of selective attention processing in the ipsilesional healthy right visual field. This is the reason why, recently we investigated the presence, the nature and the severity of a selective spatial attention deficit in the ipsilesional visual field of both left neglect and left hemianopic patients in order to understand to which extent the nature of the deficit in the contralesional visual field (attentional or visual) could determine the nature of the ipsilesional attentional deficit (Chokron, Peyrin, \& Perez, 2019). To reach this aim, we used a letterdetection task (Chokron, Brickman, Wei, \& Bucshbaum, 2000; Tabert et al., 2000) to test if right brain-damaged patients suffering from either left unilateral spatial neglect (LN) or left homonymous hemianopia (LH) may present a deficit of selective attention, in their right ipsilesional visual field as compared to normal controls. This study brought evidence for the presence of a non-lateralized attentional deficit in left neglect patients as well as a subtle attentional deficit in the ipsilesional visual field of left hemianopic patients and emphasize the need to thoroughly test for visuo-attentional capacities in the assumed 'healthy' ipsilesional visual field following unilateral parietal or occipital damage.

Of interest with the present discussion, neither left neglect patients nor left hemianopic patients were aware of this ipsilesional attentional deficit. 


\section{Hallucinations in hemianopic patients}

Patients with visual deprivation may experience visual hallucinations apart from blindness, as it has been reported in the Charles Bonnet Syndrome (CBS) (see for review, Fernandez, Lichtstein and Vieweg, 1997). As a matter of fact, in 1769, Charles Bonnet described in his 89 year-old grandfather who suffered from a cataract-induced blindness visions of men, women, birds and buildings that changed in size, shape and place (De Morsier, 1967 ; Rosenbaum et al., 1987). Importantly, these hallucinations were reported although the elderly man did not present any sign of cognitive deficit. CBS was thus defined as visual hallucinations in elderly patients free of optic nerve impairment and with no concurrent psychiatric or cognitive disturbance (De Morsier, 1967 ; Bartlett, 1951). However, the definition of CBS was subsequently extended to describe "any state of visual hallucinations in the elderly irrespective of accompanying symptomatology" (Berrios and Brook, 1982). Nowadays, clinicians commonly associate CBS with eye and brain disease, probably considering that visual hallucinations after ocular lesions or after postchiasmatic lesions are both signs of CBS. However, as we present below, hallucinations in homonymous hemianopia may be another form of dissociation between perception and awareness due to the cortical lesion. Indeed, in addition to anosognosia, blindsight, and sightblindness, hemianopic patients can also experience visual hallucinations in their contralesional visual field or even in their entire visual field, they are not always aware of. Visual hallucinations are typically defined as visual perceptions that are completely removed from reality (i.e. perceptions without stimulus; Borruat, 1999). Interestingly and not often reported neither in the literature nor during clinical examination, hemianopic patients can also 
experience visual hallucinations in their blind contralesional visual field. However, in our view, this phenomenon should be studied conjointly with other dissociation between perception and awareness such as anosognosia, blindsight and sightblindness.

The hallucinations experienced by hemianopic patients can be simple (e.g. points, lines, geometric shapes) or complex (e.g. objects, animals, people or animated scenes) and can involve the entire visual field or just part of it (Panayiotopoulos, 1999). Hemianopic patients are usually not aware that the visual perceptions in their blind visual field are in fact hallucinations. Indeed, being aware of it requires for the hemianopic patient to confront these visual perceptions to another sensory modality which is not systematic. Most of the time, hemianopic patients may experience visual perception in their blind visual field as if they had at least partly recovered from their visual field defect. When at some occasions the patient understands that what is perceived does not really exist, he/she can express negative feelings or fear of it and very often does not tell anybody about it. As a matter of fact, hemianopic patients are often afraid of being labeled "crazy" if they mention the hallucinations they experience on their own. Surprisingly, visual hallucinations in hemianopic patients have not been systematically researched perhaps, in part, because there a lack of specific and standardized questionnaire that could be easily used by practitioners. We have recently developed such a questionnaire for hemianopic patients and more generally, for patients with neurological visual impairment, named the Questionnaire for Evaluating Visual Hallucinations in Homonymous Hemianopia Patients (abbreviated as the "Q3H" questionnaire) (Perez et al., 2014). For a given patient, this questionnaire enables characterization of their hallucinations (i.e. type, frequency, etc.), including determining the extent to which they are aware of the phenomenon. Studying hallucinations in hemianopic patients reveal that they can vary in frequency and intensity, in time (instantaneous or enduring) and in complexity (simple or complex). However, the origin of these hallucinations remains poorly understood, although they are thought to depend on 
lesion location (Alfaro, Concepción, Merabet, \& Fernández, 2006). In hemianopic patients, visual hallucinations could result from compensatory hyperactivation of neighboring tissue (Braun, Dumont, Duval, Hamel-Hébert, \& Godbout, 2003; Rafique, Richards, \& Steeves, 2015). Thus, it has been reported that that the peri-lesional area of the visual cortex can generate visual hallucinations whose complexity depends on the lesion site (Kölmel, 1985): simple hallucinations would result from activation of the primary cortex, and complex hallucinations, from activation of the association cortex. Additionally, other studies have demonstrated that complex visual hallucinations can be triggered by stimulation of the temporo-occipital or the parieto-occipital lobe (Rafique et al., 2015). Over the past 5 years, our group and others have suggested that the side of the occipital lesion might be an important factor in the nature and severity of visual impairments in hemianopic patients (Perez et al., 2013; Cavezian et al., 2015). Similarly, Walters, Harrison, Williamson, and Foster (2006) investigated whether complex visual hallucinations caused by an occipital lesion might be linked to the lesion side and to patients' emotional valence. In their study, they systematically searched for hallucinations in left or right brain-damaged patients and recorded the side of the hallucination, as well as its emotional valence. They then assessed the associated perceptual deficits, including loss of vision within a visual field (left or right), loss of vision within a visual quadrant, allochiria, or extinction upon presentation of concurrent bilateral stimuli to the left and the right visual field. Of the fifteen patients experiencing visual hallucinations within the left hemispace, ten had at least one visual field defect, all of which $(10 / 10 ; 100 \%)$ were in the left visual field. In other words, among patients with a left visual field defect (right brain-damage), the hallucinations always occurred in the blind, contralesional visual field. In addition, all of the patients had associated negative affective valence to these events. With a total of ten patients experiencing visual hallucinations within the right hemispace, only four patients had demonstrated at least one visual field defect (tested by confrontation test only). All four of these (100\%) were within 
the left visual field (right-side lesion), and three of them (75\%) had an associated positive emotional valence. According to this study, it seems that the emotional valence of the hallucination depends on the side of its apparition rather than on the lesion side. However, all the patients (100\%) with visual field defects in this study had left visual field defects. No right visual field defects were detected across confrontational tasks for any of the patients. Thus, the fact that only patients with right-side lesions reported visual hallucinations suggests an effect of the lesion side on the occurrence of hallucinatory phenomena. This study suggests that the side of the occipital lesion determines the occurrence of visual hallucinations whereas the visual field of apparition could influence the emotional valence, with more frequent hallucinations in the blind, contralesional visual field than in the ipsilesional visual field, as reported in the previously cited study by Walters et al. (2006). Regardless, further studies are necessary to elucidate the link between the lesion side, the visual field of apparition and the various parameters of visual hallucinations (nature, frequency, severity, similarity with mental imagery, emotional valence, etc.). Interestingly, preliminary results from our group current studies using the $\mathrm{Q} 3 \mathrm{H}$ questionnaire suggest that the occurrence and type of visual hallucinations in hemianopic patients might strongly depend on the extent and on the location of the lesion.

\section{Discussion and Conclusion}

Damage or disconnection of all or some parts of the primary visual cortex (V1) results in a region of blindness (a scotoma) in the corresponding portion of the visual field (Holmes, 1918). In addition, in the present review, we have described four types of dissociations between perception and awareness that had never been put together to our knowledge despite the fact they represent behavioural manifestations, in addition to the visual field defect, of the damage or disconnection of V1 and the visual system. Indeed, as above-discussed, after a unilateral lesion of the occipital lobe, patients suffering from homonymous hemianopia: (1) are not always completely aware of their deficit, (2) present some residual, implicit capacities in their blind 
visual field such as blindsight, (3) may suffer from a subtle ipsilesional visual deficit in their ipsilesional (thought to be healthy) visual field although without being aware of it, (4) may experience visual hallucinations in their blind visual field without knowing that these perceptions are not real. These four phenomena which accompanies homonymous hemianopia remind us that contrary to pre-chiasmatic visual deficits, the lesion of $\mathrm{V} 1$, by disconnecting the eye from the cortical visual system induces a dissociation between visual perception and awareness that may take several forms. As pointed out by Mazzi et al. (2019) blindsight has been influential in guiding neural models of phenomenal awareness, however, the other associated signs we described in the present review had yet received less interest although they may suggest a more complex role for V1 in conscious visual experience than what has been yet discussed (see e.g. Mazzi et al., 2019 and Cowey, 2009, Cowey \& Stoerig, 2004 for discussion). Indeed, it could be the case that these phenomena are both part of a more general dysfunction and not independent one from each other. As a matter of fact, both blindsight and visual hallucinations in the blind visual field could major anosognosia by providing respectively implicit (real) and explicit (unreal) visual perceptions to the patient. In a contralesional visual field filled with implicit and illusory visual perception, it becomes more difficult for a patient to be aware of his/her visual field defect. Although in Celesia and colleagues' study (1997), most of the patients with visual hallucinations were aware of their deficit, apparently infirming our hypothesis, these authors have proposed an alternative explanation very close to ours. According to these authors, anosognosia for hemianopia could result from a perceptual filling of the field loss by a phenomenon close to our lack of perception of the blind spot. Although it is difficult to imagine that the whole contralesional field defect can be filled out, a completion of the blind visual field has been reported in hemianopic patients, that is, in certain circumstances, patients describe that their scotoma is filled out by the surrounding scene (Warrington, 1962; Sergent, 1988; Mc Carthy, James-Galton and Plant, 2006). This 
phenomenon which states in between blindsight and visual hallucinations could in part explain anosognosia for hemianopia.

In addition, the presence of an ipsilesional although subtle deficit in the ipsilesional visual field such as sightblindness could decrease the difference in visual experience in both visual fields, thus increasing anosognosia for the contralesional visual field defect. Anyway, as Celesia et al. (1997) claim, attempts to explain anosognosia in hemianopic patients with a single theory are destined to failure because of the complexities of "awareness." These authors proposed that unawareness in these patients may thus be due to different reasons such as: failure of discovery of the deficits, severe hemineglect, generalized cognitive impairment, "filling in" process, or to a combination of these factors. From the present review, we could reasonably add that blindsight, sightblindness and visual hallucinations can also interact and play a role in being aware or not of the visual field defect after a post-chiasmatic lesion.

On the other hand, visual hallucinations could in part be the product of the implicit visual perception (blindsight) in the contralesional visual field. Indeed, currently, since hallucinations had only be scarcely studied, it is still difficult to understand how implicit perceptions could participate to the construction of explicit visual hallucinations, but this certainly deserves some future research to thoroughly understand how the lesion of V1 alter both implicit and explicit visual sensations as well as the interaction between them. Recent neuro-anatomical studies investigated the role of pulvinar and superior colliculus in blindsight (see for example, Kinoshita et al., 2019), however, further research is needed to understand the cortical and subcortical substrate of the other behavioural phenomena present in hemianopic patients such as anosognosia, sightblindsness and visual hallucinations. Recently, blindsight has been hypothesized to depend partly upon the interaction between the damaged and the non-damaged hemisphere (Celeghin et al., 2015; 2017; Silvanto, Walsh \& Cowey, 2009), our recent findings suggest that this could also be the case for ipsilesional deficits in patients with unilateral parietal 
or occipital lesions (Chokron et al., 2019). In the same way, one cannot exclude the role of an interaction between the lesioned and the non-lesioned hemisphere in the production of visual hallucinations. Further studies dealing with the interaction between the visual field defect, anosognosia for it, blindsight, sightblindness and visual hallucinations should thus take into account the different neuroanatomical correlates of these phenomena, that is : a destruction or disconnection of V1 both from the eye and from higher cortical centers, the integrity of the superior colliculus and the pulvinar in order to experience blindsight, a change in interhemispheric connectivity leading to sightblindness as well as probably the integrity of part of the ventral pathway in order to experience visual hallucinations. Hemianopia and its behavioral consequences represent a complex deficit that may be associated to a damage of a distributed network around the lesion of V1.

From a more clinical perspective, hemianopic patients deserve a complete neuropsychological examination including a precise evaluation of the awareness of the deficit as well as the presence, nature and duration of hallucinations. Contralesional visual field training in rehabilitation is nearly always recommended for these patients, especially using blindsight stimulation (Chokron et al, 2008; Das, Tadin and Huxlin, 2014, Cavanaugh and Huxlin, 2017), . However, training visual discrimination and attention in the ipsilesional visual field seems to be necessary given the fact that hemianopic patients often tend to use their 'healthy' visual field to compensate for their visual field defect.

\section{References}

Ajina, S., Pestilli, F., Rokem, A., Kennard, C., \& Bridge, H. (2015). Human blindsight is mediated by an intact geniculo-extrastriate pathway. eLife, 4 .

Alfaro, A., Concepción, L., Merabet, L., \& Fernández, E. (2006). An Atypical Presentation of Visual Hallucinatory Experiences Following Prolonged Blindness*. Neurocase, 12(4), 212 215.

Anton, G. (1899). Ueber die Selbstwahrnehmung der Herderkrankungen des Gehirns durch den Kranken bei Rindenblindheit und Rindentaubheit.. Arch. Psychiaf. Neruenkrankh, 32, 86-127. 
Babinski, J. (1918). Anosognosie. Revue neurol, 31, 365-367.

Bartlett, J.E.A. (1951) A case of organized visual hallucinations in an old man with cataracts and their relation to the phenomena of the phantom limb. Brain 74:363-373.

Berrios, G.E., Brook, P. (1982) The Charles Bonnet syndrome and the problem of visual perceptual disorders in the elderly. Age Aging 11:17-23.

Bisiach, E., Vallar, G., Perani, D., Papagno, C., Berti, A. (1986). Unawareness of disease following lesions of the right hemisphere: anosognosia for hemiplegia and anosognosia for hemianopia. Neuropsychologia, 24(4):471-82.

Bola, M., Gall, C., \& Sabel, B. A. (2013a). The Second Face of Blindness: Processing Speed Deficits in the Intact Visual Field after Pre- and Post-Chiasmatic Lesions. PLoS ONE, 8(5).

Bola, M., Gall, C., \& Sabel, B. A. (2013b). "Sightblind": Perceptual Deficits in the "Intact" Visual Field. Frontiers in Neurology, 4.

Borruat, F. (1999). Hallucinations et illusions visuelles, des symptomes souvent méconnus du praticien. Klinische Monatsblätter für Augenheilkunde, 214(05), 324-327.

Braun, C. M. J., Dumont, M., Duval, J., Hamel-Hébert, I., \& Godbout, L. (2003). Brain modules of hallucination: an analysis of multiple patients with brain lesions. Journal of Psychiatry \& Neuroscience, 28(6), 432-449.

Breitmeyer, B. G. (2014). Contributions of magno- and parvocellular channels to conscious and non-conscious vision. Philosophical Transactions of the Royal Society B: Biological Sciences, $369(1641), 20130213$.

Brogaard, B. (2015). Type 2 blindsight and the nature of visual experience. Consciousness and Cognition, 32, 92-103.

Cavézian, C., Gaudry, I., Perez, C., Coubard, O., Doucet, G., Peyrin, C., . . Chokron, S. (2010). Specific impairments in visual processing following lesion side in hemianopic patients. Cortex, 46(9), 1123-1131.

Cavézian, C., Perez, C., Peyrin, C., Gaudry, I., Obadia, M., Gout, O., \& Chokron, S. (2015). Is there an ipsilesional deficit in hemianopia? The question of sightblindness in the 'intact' visual field. Cortex, 69, 166-174.

Das, A., Tadin, D., Huxlin, K.R. (2014). Beyond blindsight: properties of visual relearning in cortically blind fbeauields. J Neurosci., 35, 11652-64.

Cavanaugh, M.R., Huxlin, K.R. (2017). Visual discrimination training improves Humphrey perimetry in chronic cortically induced blindness. Neurology. 88 (19), 1856-1864.

Celeghin, A., Barabas, M., Mancini, F., Bendini, M., Pedrotti, E., Prior, M., . . Marzi, C. A. (2015). Speeded manual responses to unseen visual stimuli in hemianopic patients: What kind of blindsight? Consciousness and Cognition, 32, 6-14.

Celeghin, A., Diano, M., De Gelder, B., Weiskrantz, L., Marzi, C. A., \& Tamietto, M. (2017). Intact hemisphere and corpus callosum compensate for visuomotor functions after early visual cortex damage. Proceedings of the National Academy of Sciences, 114(48), 10475-10483.

Celesia, G. G., Brigell, M. G., \& Vaphiades, M. S. (1997). Hemianopic anosognosia. Neurology, 49(1), 88-97. 
Chokron, S., Brickman, A. M., Wei, T., \& Bucshbaum, M. S. (2000). Hemispheric asymmetry for selective attention. Brain Research Cognitive Brain Research, 9, 85-90.

Chokron, S., Perez, C., Obadia, M., Gaudry, I., Laloum, L., \& Gout, O. (2008). From blindsight to sight: cognitive rehabilitation of visual field defects. Restorative neurology and neuroscience, 26, 305-320.

Chokron, S., Perez, C., \& Peyrin, C. (2016). Behavioral Consequences and Cortical Reorganization in Homonymous Hemianopia. Frontiers in Systems Neuroscience, 10.

Chokron, S., Peyrin, C., \& Perez, C. (2019). Ipsilesional deficit of selective attention in left homonymous hemianopia and left unilateral spatial neglect. Neuropsychologia, 128, 305-314.

Cowey, A. (2009). The blindsight saga. Experimental Brain Research, 200(1), 3-24.

Cowey, A., \& Stoerig, P. (2004). Stimulus cueing in blindsight. Progress in Brain Research, , 261-277.

Critchley, M. (1949). The problem of awareness or non-awareness of hemianopic field defects. Trans Ophthalmol SOC UK, 69, 95-109.

de Morsier G. (1967). The Charles Bonnet syndrome : visual hallucinations in the aged without mental deficiency. .Ann Med Psychol (Paris). 2(5):678-702.

Fernandez, A., Lichtshein, G., Vieweg, W.V.(1997). The Charles Bonnet syndrome : a review. J Nerv Ment Dis., 185(3):195-200.

Fayel, A., Chokron, S., Cavézian, C., Vergilino-Perez, D., Lemoine, C., \& Doré-Mazars, K. (2014). Characteristics of contralesional and ipsilesional saccades in hemianopic patients. Experimental Brain Research, 232(3), 903-917.

Gainotti, G. (2019). History of Anosognosia. Frontiers of Neurology and Neuroscience, 44, 75-82.

Garric, C., Sebaa, A., Caetta, F., Perez, C., Savatovsky, J., Sergent, C., \& Chokron, S. (2019). Dissociation between objective and subjective perceptual experiences in a population of hemianopic patients: A new form of blindsight? Cortex, 117, 299-310.

Hadid, V., \& Lepore, F. (2017). From Cortical Blindness to Conscious Visual Perception: Theories on Neuronal Networks and Visual Training Strategies. Frontiers in Systems Neuroscience, 11 .

Heilman, K. M., \& Abell, T. V. D. (1980). Right hemisphere dominance for attention: The mechanism underlying hemispheric asymmetries of inattention (neglect). Neurology, 30(3), 327.

Hess, R. F., \& Pointer, J. S. (1989). SPATIAL AND TEMPORAL CONTRAST SENSITIVITY IN HEMIANOPIA. Brain, 112(4), 871-894.

Holmes, G. (1918). Disturbances of vision by cerebral lesions. British Journal of Ophthalmology, 2(7), 353-384.

Kentridge, R. W. (2015). What is it like to have type-2 blindsight? Drawing inferences from residual function in type-1 blindsight. Consciousness and Cognition, 32, 41-44. 
Kinoshita, M., Kato, R., Isa, K., Kobayashi, K., Kobayashi, K., Onoe, H., \& Isa, T. (2019). Dissecting the circuit for blindsight to reveal the critical role of pulvinar and superior colliculus. Nature Communications, 10(1).

Koehler, P., Endtz, L., Velde, J., \& Hekster, R. (1986). Aware or non-aware. Journal of the Neurological Sciences, 75(3), 255-262.

Kolmel, H. W. (1985). Complex visual hallucinations in the hemianopic field.. Journal of Neurology, Neurosurgery \& Psychiatry, 48(1), 29-38.

Leh, S. E. (2006). Unconscious vision: new insights into the neuronal correlate of blindsight using diffusion tractography. Brain, 129(7), 1822-1832.

Leopold, D. A. (2012). Primary Visual Cortex: Awareness and Blindsight. Annual Review of Neuroscience, 35(1), 91-109.

Levine DN. (1990). Unawareness of visual and sensorimotor defects: a hypothesis. Brain Cogn. $13,233-81$.

Marzi, C. A., Tassinari, G., Aglioti, S., \& Lutzemberger, L. (1986). Spatial summation across the vertical meridian in hemianopics: a test of blindsight. Neuropsychologia, 24(6), 749-758.

Mazzi, C., Bagattini, C., \& Savazzi, S. (2016). Blind-Sight vs. Degraded-Sight: Different Measures Tell a Different Story. Frontiers in Psychology, 7.

Mazzi, C., Savazzi, S., Silvanto, J. (2019). On the "blindness" of blindsight: What is the evidence for phenomenal awareness in the absence of primary visual cortex (V1)? Neuropsychologia, 128:103-108.

McCarthy, R.A., James-Galton, M., Plant, G.T. (2006). Form completion across a hemianopic boundary: behindsight? Neuropsychologia.44, 1269-81.

Mikellidou, K., Arrighi, R., Aghakhanyan, G., Tinelli, F., Frijia, F., Crespi, S., . . Morrone, M. (2019). Plasticity of the human visual brain after an early cortical lesion. Neuropsychologia, $128,166-177$.

Overgaard, M. (2011). Visual experience and blindsight: a methodological review. Experimental Brain Research, 209(4), 473-479.

Overgaard, M., Fehl, K., Mouridsen, K., Bergholt, B., \& Cleeremans, A. (2008). Seeing without Seeing? Degraded Conscious Vision in a Blindsight Patient. PLoS ONE, 3(8), 3028.

Pambakian, A. L. M., \& Kennard, C. (1997). Can visual function be restored in patients with homonymous hemianopia? British Journal of Ophthalmology, 81(4), 324-328.

Panayiotopoulos, C. P. (1999). Elementary visual hallucinations, blindness, and headache in idiopathic occipital epilepsy: differentiation from migraine. Journal of Neurology, Neurosurgery \& Psychiatry, 66(4), 536-540.

Paramei, G. V., \& Sabel, B. A. (2008). Contour-integration deficits on the intact side of the visual field in hemianopia patients. Behavioural Brain Research, 188(1), 109-124.

Perenin, M., \& Jeannerod, M. (1975). Residual vision in cortically blind hemiphields. Neuropsychologia, 13(1), 1-7.

Perez, C. \& Chokron, S. (2014). Rehabilitation of homonymous hemianopia: insight into blindsight. Front Integr Neurosci. 22, 8:82. 
Perez, C., Gillet-Ben Nejma, I., Allali, S., Boudjadja, M., Caetta, F., Gout, O., . . Chokron, S. (2014). Hémianopsie latérale homonyme : amputation du champ visuel, perception implicite et hallucinations visuelles. Revue de Neuropsychologie, Neurosciences cognitives et cliniques, 6 , $238-255$.

Perez, C., Peyrin, C., Cavézian, C., Coubard, O., Caetta, F., Raz, N., . . Chokron, S. (2013). An fMRI Investigation of the Cortical Network Underlying Detection and Categorization Abilities in Hemianopic Patients. Brain Topography, 26(2), 264-277.

Peyrin, C., Chokron, S., Guyader, N., Gout, O., Moret, J., \& Marendaz, C. (2006). Neural correlates of spatial frequency processing: A neuropsychological approach. Brain Research, 1073-1074, 1-10.

Poggel, D. A., Treutwein, B., \& Strasburger, H. (2011). Time will tell: Deficits of temporal information processing in patients with visual field loss. Brain Research, 1368, 196-207.

Pöppel, E., Held, R., \& Frost, D. (1973). Residual Visual Function after Brain Wounds involving the Central Visual Pathways in Man. Nature, 243(5405), 295-296.

Rafique, S., Richards, J., \& Steeves, J. (2015). Suppression of unformed visual hallucinations in homonymous hemianopia from occipital stroke using TMS. Journal of Vision, 15(12), 1037.

Ramsøy, T. Z., \& Overgaard, M. (2004). Introspection and subliminal perception. Phenomenology and the Cognitive Sciences, 3(1), 1-23.

Rizzo, M., \& Robin, D. A. (1996). Bilateral effects of unilateral visual cortex lesions in human. Brain, 119(3), 951-963.

Rosenbaum, F., Harati, Y., Rolak, L., Freedman, M. (1987). Visual hallucinations in sane people: Charles Bonnet syndrome. J Am Geriatr Soc.35(1):66-8.

Sahraie, A., Trevethan, C. T., MacLeod, M. J., Urquhart, J., \& Weiskrantz, L. (2013). Pupil response as a predictor of blindsight in hemianopia. Proceedings of the National Academy of Sciences, 110(45), 18333-18338.

Sanchez-Lopez, J., Pedersini, C. A., Di Russo, F., Cardobi, N., Fonte, C., Varalta, V., .. . Marzi, C. A. (2019). Visually evoked responses from the blind field of hemianopic patients. Neuropsychologia, 128, 127-139.

Sanders, M., Warrington, E., Marshall, J., \& Wieskrantz, L. (1974). "Blindsight": Vision in a field defect. The Lancet, 303(7860), 707-708.

Schadow, J., Dettler, N., Paramei, G. V., Lenz, D., Fründ, I., Sabel, B. A., \& Herrmann, C. S. (2009). Impairments of Gestalt perception in the intact hemifield of hemianopic patients are reflected in gamma-band EEG activity. Neuropsychologia, 47(2), 556-568.

Sergent J. (1988). An investigation into perceptual completion in blind areas of the visual field. Brain. 111 ( Pt 2):347-73.

Silvanto, J., Walsh, V., \& Cowey, A. (2009). Abnormal functional connectivity between ipsilesional V5/MT+ and contralesional striate cortex (V1) in blindsight. Experimental Brain Research, 193(4), 645-650.

Tabert, M. H., Chokron, S., Tang, C. Y., Wei, T., Brickman, A. M., \& Buchsbaum, M. S. (2000). Visual target detection paradigm for the study of selective attention. Brain Research Protocols, 6(1-2), 80-85. 
Von Monakow, C. (1885). Experimentelle und pathologisch-anatomische Untersuchungen über die Beziehungen der sogenannten Sehsphäre zu den infracorticalen Opticuscentren und zum N. opticus. Archiv für Psychiatrie und Nervenkrankheiten, 16(2), 317-352.

Walters, R. P., Harrison, D. W., Williamson, J., \& Foster, P. (2006). Lateralized Visual Hallucinations: An Analysis of Affective Valence. Applied Neuropsychology, 13(3), 160-165.

Warrington, E.K. (1962). The completion of visual forms across hemianopic field defects. $J$ Neurol Neurosurg Psychiatry. 25, 208-17.

Weiskrantz, L. (1998). Pupillary Responses With and Without Awareness in Blindsight. Consciousness and Cognition, 7(3), 324-326.

Weiskrantz, L. (2009). Is blindsight just degraded normal vision? Experimental Brain Research, 192(3), 413-416.

Weiskrantz, L., Barbur, J. L., \& Sahraie, A. (1995). Parameters affecting conscious versus unconscious visual discrimination with damage to the visual cortex (V1).. Proceedings of the National Academy of Sciences, 92(13), 6122-6126.

Weiskrantz, L., Warrington, E. K., Sanders, M. D., \& Marshall, J. (1974). Visual capacity in the hemianopic field following a restricted occipital ablation. Brain, 97(1), 709-728.

Zhang, X., Kedar, S., Lynn, M. J., Newman, N. J., \& Biousse, V. (2006). Homonymous hemianopias: Clinical-anatomic correlations in 904 cases. Neurology, 66(6), 906-910.

Zihl, J. (2000). Rehabilitation of Visual Disorders. Hove, UK: Psychology Press.

Zihl, J. (2011). Rehabilitation of Visual Disorders After Brain Injury (2nd ed.). Hove, UK: Psychology Press.

\section{Acknowledgments}

We are grateful to the E. and B. De Rothschild Foundations (NewYork and Geneva).

\section{Acknowledgements}

The research from our group that we report in this review was sponsored by the Edmond and Benjamin de Rothschild Foundations. We would like to thank Sébastien Allali, Marie-Laure Larcinèse, Fiora Martinelli, and Ariadna Albajara for their help in distributing the Q3H

Questionnaire to hemianopic patients. 


\section{Table 1}

BEHAVIORAL PROFILES IN

DEFINITION

HOMONYMOUS HEMIANOPIA

BLINDSIGHT (SANDERS ET AL. 1974; WEISKRANTZ 1998)

BLINDSENSE (GARRIC ET AL. 2019)

SIGHTBLINDNESS (BOLA, GALL, AND SABEL 2013; CAVÉZIAN ET AL. 2010; CHOKRON, $S$; PEREZ, C ; PEYRIN 2015)

\section{HALLUCINATIONS}

KOLMEL, 1985 ; PANAYIOTOPOULOS, 1999 ; RAFIQUE ET AL, 2015 ; WALTERS ET AL., 2006)

ANOSOGNOSIA (CELESIA, BRIGELL, AND VAPHIADES 1997)
The ability to discriminate specific attributes of a visual stimulus in the contralesional visual field ...

\section{TYPE 1}

... without any form of consciousness

\section{TYPE 2}

... exhibiting non-visual experience that something occurred during a stimulation

The ability to sense visual stimuli in the blind hemifield without being able to discriminate visual features of it

Subtle visual deficits occuring in the ipsilesional visual field mistakenly considered to be unaffected

Perceptions in the blind hemifield that are completely removed from reality

\section{SIMPLE HALLUCINATION}

Visual experience of points, lines, geometric shapes

\section{COMPLEX HALLUCINATION}

Visual experience of objects, animals, people or animated scenes

Unawareness of the visual loss in the contralesional hemifield 